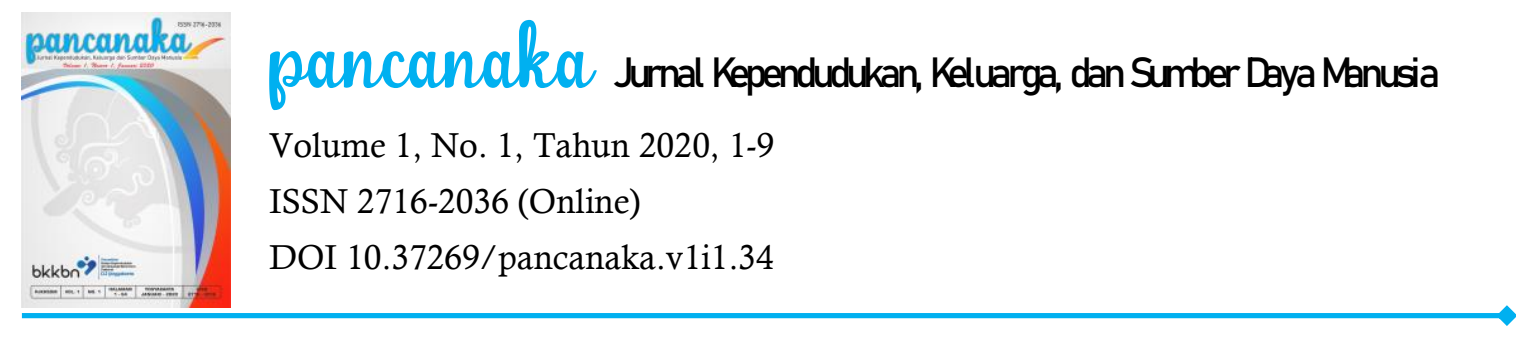

\title{
STRATEGI SMART TEST DALAM PEMBELAJARAN LATSAR CPNS DI ERA SOCIETY 5.0
}

Agus Suharsono, Balai Diklat Keuangan Yogyakarta. E-Mail: gusharpramudito@gmail.com Ana Uluwiyah, Pusdiklat BPS. E-Mail: auluwiyah@gmail.com

\begin{abstract}
Abstrak
Point penting dalam society 5.0 adalah terjadinya cross-sectional pada knowledge dan informasi, sehingga mendorong orang untuk dapat terus tumbuh dan berkembang menjadi pribadi masyarakat yang aktif. Konsep dalam society 5.0, telah mulai berkembang dalam budaya masyarakat Indonesia. Ada beberapa indikator penting, diantaranya adalah kesadaran masyarakat untuk menggunakan IT sebagai salah satu "enabler" dalam mendukung aktivitas pekerjaannya. Tulisan ini akan memberikan gambaran umum tentang salah satu metode pembelajaran yang mendukung terwujudnya budaya society 5.0 untuk meningkatkan kompetensi peserta diklat, melalui studi empiris dengan data hasil survei pada Diklat Latsar CPNS Kemenkeu. Berdasarkan hasil analisis deskriptif, diperoleh gambaran umum bahwa melalui pengembangan metode pembelajaran yang sesuai dengan budaya society 5.0, tujuan pembelajaran seperti meningkatkan kompetensi peserta lebih mudah dicapai. Alasannya karena, pengembangan metode pembelajaran, dalam paper ini menggunakan Quizziz, sesuai dengan kebutuhan dan budaya peserta yang pada dasarnya adalah $100 \%$ generasi milineal. Hal ini dapat disimpulkan, bahwa dengan budaya masyarakat yang sudah mulai bergeser ke soceity 5.0, maka pemerintah perlu melakukan inovasi atau terobosan sesuai kebutuhan masyarakat agar lebih efektif dan efisien.
\end{abstract}

Kata Kunci: soceity 5.0, metode pembelajaran, quizziz

\begin{abstract}
An important point in community 5.0 is cross-section based on knowledge and information, thus encouraging people to be able to continue to grow and develop into active community people. The concept in society 5.0, has begun to develop in the culture of Indonesian society. There are several important indicators, including public awareness to use IT as an "enabler" in supporting work activities. This paper will provide a general description of one of the learning methods that support the realization of a culture of society 5.0 to improve the competence of training participants, through empirical studies with survey data on the CPNS Latsar Training Ministry of Finance. Based on the results of descriptive analysis, a general description is obtained that through the development of learning methods that are appropriate to the culture of society 5.0, learning objectives such as increasing the competency of participants are more easily achieved. The reason is because, the development of learning methods, in this paper uses Quizizz, according to the needs and culture of the participants which is basically 100\% millennial generation. This can be concluded, that with the culture of society that has begun to shift to sociality 5.0, the government needs to innovate or breakthrough according to community needs to be more effective and efficient.
\end{abstract}

Keywords: society 5.0, learning methods, quizzzi 


\section{Pendahuluan}

Menurut Kayano Fukuda, society 5.0 diartikan sebagai "super-smart society", merupakan society baru pada tahap kelima yang mengikuti empat tahap sebelumnya yaitu masyarakat berburu, masyarakat agraris, masyarakat industri dan masyarakat informasi. Konsep utama dalam society 5.0 adalah menciptakan masyarakat yang berpusat pada manusia, dimana produk dan layanan disediakan untuk memenuhi berbagai kebutuhan potensial serta untuk mengurai kesenjangan ekonomi dan sosial, sehingga semua orang menjalani kehidupan yang nyaman dan bersemangat. Untuk itu, peran manusianya sendiri untuk berpikir dan bekerja aktif menjadi tuntutan agar mampu menyediakan layanan dan produk yang sesuai kebutuhan masyarakat pada era digitalisasi (Fukuda, 2019).

Berdasarkan konsep society 5.0 diatas, kondisi yang ada di Indonesia saat ini, sudah mulai menuju pada budaya society 5.0. Beberapa indikator diantaranya adalah, berdasarkan data yang dirilis oleh Hootsuite, Januari 2019, ada sebanyak $56 \%$ persen pengguna internet dari total penduduk Indonesia, dan 56\% tersebut aktif dalam melakukan aktivitas melalui internet. Aktivitas pengguna internet, 93\% adalah melakukan pencarian produk atau layanan yang akan dibelinya. Dukungan kuat juga dari struktur demografi Indonesia, yaitu dalam kurun waktu dekat, Indonesia akan mendapatkan bonus demografi, yaitu pada tahun 2030-2045. Hal ini menjadi indikator utama bahwa masyarakat Indonesia telah menuju society 5.0.

Untuk mendorong menciptkan iklim budaya society 5.0, sumber daya manusia (SDM) dalam pemerintahan, harus didorong untuk memiliki kompetensi dan budaya tersebut agar produk dan layanan-layanan yang diciptakan oleh pemerintah sesuai dengan kebutuhan masyarakat society 5.0. Calon Pegawai Negeri Sipil (CPNS), berdasarkan ketentuan yang berlaku, hanya diberi waktu satu tahun masa prajabatan dan harus lulus pendidikan dan pelatihan untuk dapat diangkat menjadi PNS, sehingga pendidikan dan pelatihan tersebut sangat penting bagi CPNS. Adapun dasar hukumnya adalah: Pertama, Pasal 63 ayat (4) Undang-Undang Republik Indonesia Nomor 5 Tahun 2014 Tentang Aparatur Sipil Negara mengatur bahwa untuk dapat diangakat menjadi PNS, CPNS harus melalui masa percobaan yang dilaksanakan melalui proses pendidikan dan pelatihan terintegrasi untuk membangun integritas moral, kejujuran, semangat dan motivasi nasionalisme dan kebangsaan, karakter kepribadian yang unggul dan bertanggung jawab, dan memperkuat profesionalisme serta kompetensi bidang. Kedua, Pasal 34 Peraturan Pemerintah Republik Indonesia Nomor 11 Tahun 2017 Tentang Manajemen Pegawai Negeri Sipil mengatur bahwa CPNS wajib menjalani masa percobaan prajabatan selama satu tahun melalui melalui proses pendidikan dan pelatihan yang dilakukan secara terintegrasi untuk membangun integritas moral, kejujuran, semangat dan motivasi nasionalisme dan kebangsaan, karakter kepribadian unggul dan bertanggung jawab, dan memperkuat profesionalisme serta kompetensi bidang yang hanya dapat diikuti satu kali.

Jepang memperkenalkan masyarakat society 5.0, Eropa memperkenalkan Industrial Revolution 4.0 yang melekat dengan transformasi tehnologi digital, namun masih membuat banyak pihak, termasuk aparat pemerintah masih perlu banyak perhatian. Negara lain sudah mulai mengimplementasikan dan mengambil manfaat dari Industrial Revolution 4.0, dimana teknologi tidak dianggap ancaman namun membantu memudahkan manusia ketika beraktivitas dan memberi solusi atas masalahnya (Puspitasari D. , 2019). Perkembangan teknologi informasi dan komunikasi saat ini membawa perubahan besar di bidang pendidikan yang berfungsi untuk membantu inovasi proses belajar dan meningkatkan kinerja dengan membuat, menggunakan, dan mengelola proses yang efektif dan efisien (Wanda, 2017). Perkembangan tersebut juga merambah pada pendidikan dan pelatihan bagi CPNS yang merupakan generasi millenial atau generasi Y adalah generasi yang lahir diantara tahun 1981 sampai dengan 2003 (Puspitasari S. S., 2018) atau saat tulisan ini dibuat berumur di bawah 37 tahun. Akhir tahun 2017 jumlah Pegawai Negeri Sipil di Indonesia 4.374 .349 orang dan yang berumur di bawah 37 tahun mencapai 1.512.932 orang atau 35\% (BPS, 2017). Jumlah CPNS Kemenkeu tahun 2017 menurut 
Sesjen Kemenkeu sebanyak 4.870 orang yang berasal dari: lulusan PKN STAN program D1: 2.997 orang dan program D3: 1.873 orang, rekrutmen umum 2.880 orang yang terdiri dari program D3: 2.146 orang, S1: 733, dan S2: 1 orang (Hadiyanto, 2017).

Industrial Revolution 4.0 maupun Society 5.0 merupakan keniscayaan yang perlu dihadapi dengan banyak persiapan dan tidak bisa dihindarikan. Oleh karena itu, yang bisa dilakukan adalah mempersiapkannya dengan sebaik mungkin. Salah satu persiapan yang dapat dilakukan adalah melalui pembekalan SDM baru dalam hal ini CPNS agar memiliki sikap-perilaku dan kompetensi yang sesuai dengan tuntutan pergeseran budaya society 5.0. Diperlukan cara berpikir yang kreatif dan inovatif untuk dapat turut serta dalam kemajuan ini (Ferreira \& Serpa, 2018).

Salah satu cara kreatif dalam mempersiapkan CPNS Industrial Revolution 4.0 maupun Society 5.0 adalah melalui pengembangan metode pembelajaran memanfaatkan perkembangan tehnologi informasi, misalnya smart e-learning, smart test melalui aplikasi, smart task, dan smart game. Quizziz merupakan salah satu tools yang dapat digunakan untuk mendesain metode pembelajaran smart test. Konsep smart learning wajib memanfaatkan media digitalisasi. Hal ini sesuai penelitian (Wibawanto, 2016) yaitu saat ini generasi mileneal dengan karakteristik lekat dengan gawai digital sehingga dalam pembelajaran juga perlu memanfaatkan gawai digital juga. Tulisan ini akan membahas tentang strategi smart test melalui penggunaan quizizz untuk meningkatkan pemahaman bagi peserta latsar CPNS Kemenkeu.

\section{Kajian Pustaka}

Transformasi digital mempunyai berbagai bentuk, di Jepang: Society 5.0, di Eropa: Industrial Revolution 4.0, di China: Made in China 2025, di Amerika: Industrial Internet, dan di Asia: Smart Cities. Transformasi digital akan terus mengubah segala sesuatu secara mendasar mulai dari cara kita berpikir, bersosialisasi, berkomunikasi, menganalisa, berpemerintahan, bahkan dalam melakukan perencanaan akan berubah secara fundamental dalam 5, 10, dan sudah pasti dalam 20 tahun yang akan datang. Transformasi digital akan memudahkan pemerintah dan swasta dalam memenuhi kebutuhan setiap orang sejak dari lahir sampai meninggal. Trnasformasi digital akan berdampak pada inovai, akselerasi, efidensial, produktifitas, inklusivitas, kolaborasi, dan akuntabilitas di semua sektor pembangunan (BAPPENAS, 2019).

Perdana Menteri Jepang Shinzo Abe dalam Pertemuan Tahunan Forum Ekonomi Dunia 2019 di Davos, Swiss, menjelaskan visi baru Jepang yaitu, Society 5.0 yang didefinisikan sebagai sebuah masyarakat yang berpusat pada manusia yang menyeimbangkan kemajuan ekonomi dengan penyelesaian masalah sosial melalui sistem yang sangat mengintegrasikan ruang maya dan ruang fisik. Society 5.0 akan menghubungkan dan menggerakkan segala hal, membantu mengisi kesenjangan antara yang kaya dan yang kurang beruntung. Layanan kedokteran dan pendidikan, dari tingkat dasar hingga perguruan tinggi, akan mencapai desa-desa kecil di wilayah Sub-Sahara (Prima, 2019). Society 5.0 merupakan ide implementasi teknologi dalam Industrial Revolution 4.0 yang juga mempertimbangkan aspek humaniora dengan memberikan peluang untuk menyelesaikan permasalahan sosial. Society 5.0 perlu diwujudkan dengan penelitian secara bersama-sama dengan kontribusi berbagai sektor (Faruqi, 2019).

Karakteristik Industrial Revolution 4.0, ini meliputi digitalisasi, optimalisasi, dan kustomisasi produksi, otomasi dan adapsi, human machine interaction, value added services and businesses, automatic data exchange and communication, dan memadukan penggunaan teknologi internet. Saat ini, di Indonesia sudah ada 51 perguruan tinggi negeri yang siap menggelar kuliah non tatap muka, dalam menghadapi era disrupsi teknologi informasi dan komunikasi menuju cyber university sudah banyak diterapkan di negara maju (Iswan \& Herwina, 2018). Society 5.0 dapat didefinisikan sebagai "masyarakat intelijen", di yang ruang fisik dan dunia maya sangat terintegrasi. Meski fokus tentang kemanusiaan, Society 
5.0 mengacu inovasi dalam sains dan teknologi dengan tujuan menyeimbangkan masalah sosial. Society 5.0 muncul dari masyarakat pemburu-pengumpul, pertanian masyarakat, masyarakat industri dan masyarakat informasi (Salgues, 2018).

Implementasi Industrial Revolution 4.0, maupun Society 5.0 dalam skala kecil pada bidang pendidikan dan pengembangan ASN adalah pemanfaatan internet sebagai media pembelajaran dan alat ukur peningkatan kompetensi peserta. Aplikasi untuk mengukur peningkatan kompetensi dengan quiz otomatis ada beberapa yaitu: QMP-TodaysMeet; Padlet; Mentimeter; Kahoot; Quizizz; ThatQuiz; GoConqr; ClassMarker; Edmodo; Scorative, atau Google-Flubaroo (Jamro, 2017). Pembelajaran untuk generasi milenial pada abad ke-21 ini sebaiknya memanfaatkan teknologi informasi misalnya aplikasi quizizz yang terbukti meningkatkan kompetensi pembelajaran dengan cara yang menarik dan kolaboratif sesuai dengan pembelajaran yang berpusat pada pembelajar (Balasubramanian, 2017).

Perkalan Nomor 12 Tahun 2018 tentang Latsar CPNS mengatur bahwa untuk mencapai kompetensi PNS sebagai pelayan masyarakat yang berkarakter dan profesional kurikulum Latsar terdiri dari dua bagian yaitu pembentukan karakter PNS dan penguatan kompetensi teknis bidang tugas. Salah satu materi untuk pembelajaran agenda kedudukan dan peran PNS dalam NKRI adalah Manajemen ASN. Materi Manajemen ASN untuk membekali peserta dengan pengetahuan tentang kedudukan, peran, hak dan kewajiban, dan kode etik ASN, konsep sistem merit dalam pengelolaan ASN, dan pengelolaan ASN. Metode pembelajaran Mata Diklat Manajemen ASN berbasis experiencial learning, melalui kombinasi metode ceramah interaktif, diskusi, studi kasus, simulasi, menonton film pendek, studi lapangan dan demonstrasi (Wahyudi Kumorotomo, 2015).

Metode pembelajaran adalah upaya memberi wawasan kognitif, menumbuhkan kemampuan afektif, dan psikomotorik peserta didik dengan cara menghayati dan mengamalkannya (Nata, 2009). Metode pembelajaran yang tepat berpengaruh terhadap motivasi belajar siswa sehingga pilihannya tidak boleh yang menyebabkan peserta tidak senang, bosan, dan tidak bersemangat (Mujiman, 2007). Namun tidak ada metode pembelajaran satu lebih baik dari yang lain karena metode pembelajaran tergantung pada tujuan yang ingin dicapai, karakteristik siswa, dan nilai-nilai masyarakat. Pengajar harus siap menggunakan berbagai model pembelajaran dan mengaitkan metode pembelajaran dengan kreatif dalam suatu pembelajaran (Arends, 2013). Agar pembelajaran berpusat pada pembelajar perlu penggunaan media pembelajaran yang dapat meningkatkan interaksi antar pengajar dan pembelajar dan membantu pembelajar memahami materi pembelajaran (Mashoedah, 2015).

Quizizz adalah alat penilaian formatif yang menyenangkan, multiplayer, gratis, dan berfungsi di semua perangkat (komputer, tablet, smartphone) dengan aplikasi iOS, Android, dan Chrome. Setiap siswa atau kelompok membutuhkan satu perangkat, namun tidak perlu membuat akun di quizizz, dapat langsung bergabung cukup dengan memasukkan game code. Quiz dapat kita bagikan untuk digunakan pihak lain (quizizz, 2019). Quizizz menyenangkan karena menggunakan elemen lucu seperti meme, avatar dan gamification yang membuat siswa semangat belajar. Quizizz dapat juga menampilkan data analisis kinerja masing-masing peserta yang terperinci, online dan dapat diundul sebagai spreadsheet Excel (quizizz, 2019). Quizizz dapat mentransfer banyak tugas, mengulang, menghibur, dan jumlah parsisipannya banyak (Eser Çeker, 2017). Quizizz pertanyaan dan jawaban muncul di layar komputer atau HP masing-masing peserta, sehingga cenderung individual. Namun quizizz dapat memberikan analisis jawaban, sebagai evaluasi, artinya untuk evaluasi lebih tepat menggunakan Quizizz. Penggunaan quizizz membuat pembelajar aktif dan konsentrasi pada materi pembelajaram, untuk itu pengajar dihimbau untuk menerapkannya (Suo Yan mei, 2018). Untuk evaluasi formatif quizizz menginformasikan dan mengidentifikasi jawaban yang salah maupun jawaban yang benar untuk masingmasing pembelajar, sehingga lebih efektif karena diketahui materi apa yang perlu diperbaiki (Huisman, 2018). 


\section{Metode Penelitian}

Penelitian di bidang pendidikan,banyak situasi eksperimental dimana peneliti perlu menggunakan kelompok utuh, Pendidikan melarang pembentukan kelompok partisipan karena akan mengganggu pembelajaran di kelas sehingga metode panelitian yang cocok adalah kuasi-eksperimental (Creswell, 2015). Penelitian ini bersifat kualitatif yang menurut Lofland \& Lofland sumber data utama dalam penelitian kualitaitif adalah kata-kata dan tindakan, selebihnya adalah data tambahan seperti dokumen (Moleong, 2015). Sedangkan yang menjadi instrumen penelitian adalah peneliti itu sendiri (Sugiyono, 2015). Namun untuk mendapatkan data sebanyak mungkin dan guna mempermudah dalam mengumpulkan data juga digunakan instrumen lain berupa lembar evaluasi, lembar kuesioner, catatan observasi, dan dokumentasi. Pengumpulan data dalam penelitian ini melalui test, observasi, dan poliangulasi. Data yang terkumpul dianalisis dengan analisis logiko-induktif yaitu sebuah proses berpikir yang menggunakan logika untuk memahami pola dan kecenderungan dalam data melalui tiga tahap yaitu pengkodean, mendeskripsikan karakteristik utama, dan menginterpretasikan data (Mertler, 2011). Penelitian ini menggunakan metode analisis statistik deskriptif dan analisis kualitatif. Analisis deskriptif digunakan untuk melihat nilai-nilai pemusatan dari distribusi data hasil survei. Sedangkan analisis kualitatif digunakan untuk memperkuat hasil analisis dekriptif. Sumber data yang digunakan adalah data primer, yang diambil dalam kelas latsar CPNS Golongan III Kemenkeu tahun 2019 dengan 30 peserta dengan 8 kali tindakan kuasi-eksperimen smart test. Variabel yang digunakan dalam penelitian adalah nilai hasil smart test peserta.

\section{Hasil dan Pembahasan}

Smart test dilakukan dengan menggunakan tools Quizziz yang dapat diakses melalui alamat link https://quizizz.com/. Adapun prosedur pelaksanaan smart test yaitu sebagai berikut: 1) Pengampu membuka test (mengundang peserta ) dengan memberikan kode tertentu kepada peserta; 2) Peserta melalui Smartphone masing-masing mengakses quiz/test dengan alamat https://quizizz.com/; 3) Peserta menginput game kode dari pengampu; 4) Pengampu menunggu sampai keseluruhan peserta berpartisipasi dalam test; 5) Setelah seluruh peserta check in ke dalam test, maka pengampu memulai test online; 6) Score nilai selama proses penyelesaian test transparan terbuka di layar depan kelas; dan 7) Seluruh peserta terpacu untuk menyelesaikan dengan sebaik dan secepat mungkin agar menjadi juara. Pada proses pelaksanaan test tersebut, keaktifan, ketelitian dan kecepatan peserta terasah dengan baik. Peserta dituntut untuk bisa menyelesaikan smart test dengan jujur dan cepat, karena masing-masing memiliki soal yang sama, meski soal yang muncul diacak untuk masing-masing peserta. Hal ini menjadi modal utama dalam pengembangan SDM agar memiliki sikap-perilaku dan kompentensi sesuai harapan masyarakat society 5.0.

Berdasarkan hasil explorasi data, tingkat akurasi hasil test dengan quizziz pada 8 tahapan adalah rata-rata diatas $70 \%$. Hal ini menandakan bahwa peserta dapat mengikuti smart test dengan sangat baik dan sesuai tujuan pembelajaran. Lebih lengkapnya dapat dilihat pada Gambar 1. 


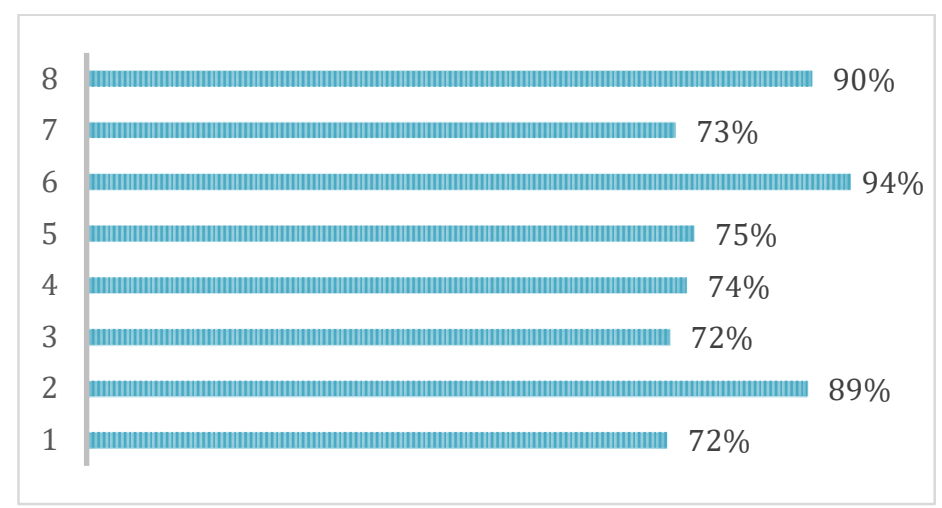

Gambar 1. Grafik Tingkat Akurasi Pelaksanaan Test

Apabila dikategorikan ke dalam 3 kelompok, yaitu nilai hasil test $<70,70-80$, dan $81-100$, kelompok nilai $<70$ ada sebanyak $18 \%$, hal ini berarti lebih dari $80 \%$ peserta memiliki nilai yang sangat memuaskan. Hal ini menunjukkan bahwa pembelajaran dapat diterima dan dipahami dengan baik. Untuk lebih lengkapnya dapat dilihat pada Gambar 2.

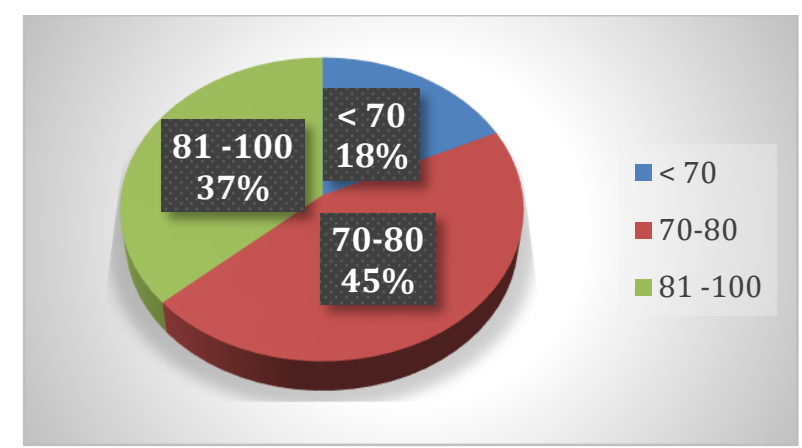

Gambar 2. Persentase Kelompok Nilai Hasil Test

Apabila dilihat lebih detail, jumlah peserta yang mendapatkan nilai 100 ada sebanyak $41 \%$ orang dan nilai 80 ada sebanyak $50 \%$. Hasil tersebut sangat memuaskan dan dapat dikatakan bahwa pelaksaan smart test melalui quizziz mampu meningkatkan kompetensi peserta. Untuk lebih detailnya dapat dilihat pada Gambar 3.

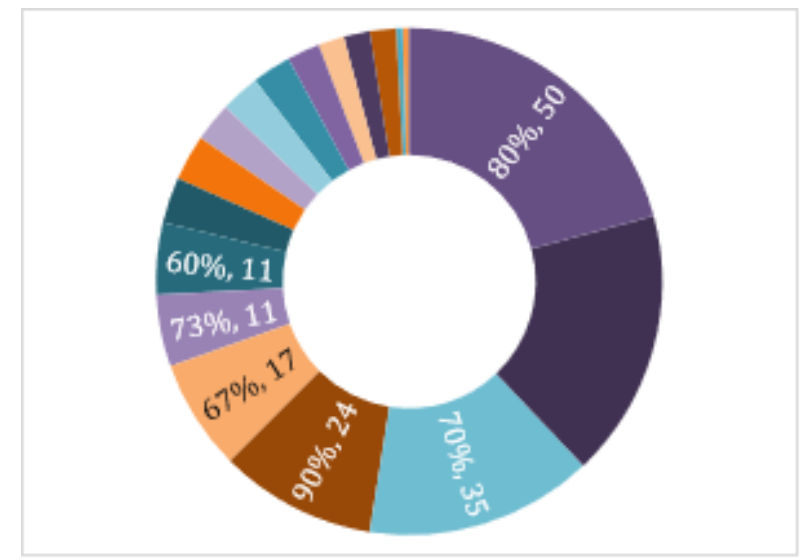

Gambar 3. Hasil Nilai Test Peserta Diklat Latsar CPNS Melalui Quizziz 
Apabila dikelompokkan kembali dengan range 10, maka kelompok nilai 80 merupakan frekuensi tertinggi. Hal ini menandakan bahwa rata-rata kelas kompetensi peserta sebesar 80. Hasil yang cukup memuaskan dan dapat disimpulkan bahwa smart test melalui Quizziz mudah, cepat dan menarik. Untuk lebih jelasnya dapat dilihat pada Gambar 4.

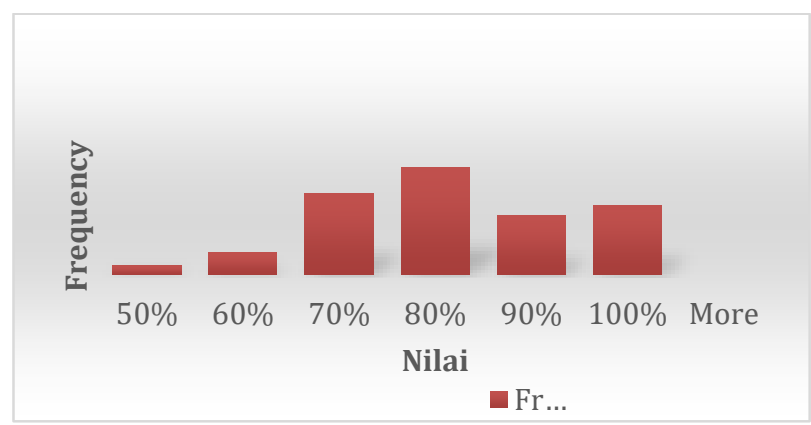

Gambar 4. Histogram Frekuensi Distribusi Data Peserta

Berdasarkan analisis deskriptif diperoleh informasi bahwa rata-rata nilai peserta 80 , dengan sebaran yang sangat baik, diversifikasi nilai tidak terlalu jauh, sehingga bisa diartikan bahwa hampir $80 \%$ peserta dapat mengikuti pembelajaran dengan baik. Hal ini ditunjukkan dari nilai standar error yang sangat kecil, yaitu sebesar 0,009 dan sample variance 0,02 . Minimum nilai adalah 5 , tetapi jumlahnya hanya 1 . Hal ini terjadi mungkin faktor jaringan internet dari peserta tersebut terputus, sehingga tidak dapat melanjutkan atau menyelesaikan test. Hasil analisis deskriptif dapat dilihat pada Tabel 1.

Tabel 1. Hasil Pengujian Analisis Deskriptif

\begin{tabular}{lr}
\hline Ukuran Pemusatan & Hasil Uji \\
\hline Mean & 0,796219 \\
Standard Error & 0,009337 \\
Median & 0,8 \\
Mode & 0,8 \\
Standard Deviation & 0,144951 \\
Sample Variance & 0,021011 \\
Kurtosis & 3,328965 \\
Skewness & $-0,90955$ \\
Range & 0,95 \\
Minimum & 0,05 \\
Maximum & 1 \\
Sum & 191,8889 \\
Count & 240 \\
Confidence Level (95,0\%) & 0,018393 \\
\hline
\end{tabular}

Berdasarkan analisis kuantitatif diatas, dapat disimpulkan bahwa pengembangan metode smart test melalui Quizziz dapat diterima dengan baik oleh peserta, dan dapat meningkatkan kompetensi peserta. Hal tersebut sangat mendorong peserta untuk dapat memiliki sikap-perilaku dan kompetensi sesuai harapan society 5.0. Harapannya dengan 
SDM yang mumpuni, maka pemerintah dapat lebih produktif menghasilkan produk dan layanan yang dibutuhkan oleh masyarakat dengan sangat mudah.

Kelebihan smart test melalui quizziz memang sangat dapat dirasakan, akan tetapi terdapat beberapa kendala. Menurut pendapat peserta, beberapa kendala diantaranya adalah: jaringan internet, banyak yang mengalami salah menekan tombol jawaban, dan tergesa-gesa karena waktu yang pendek, serta tidak dapat dikerjakan secara berkelompok. Kekurangan-kekurangan berdasarkan pendapat peserta, pada dasarnya menjadi dorongan bagi peserta untuk memiliki sikap-perilaku yang teliti, bekerja cepat, dan smart. Karakteristik peserta tersebut merupakan modal dasar untuk memasuki society 5.0.

\section{Kesimpulan}

Berdasarkan pembahasan diatas, maka dapat disimpulkan bahwa strategi smart test melalui tools Quizziz mampu menjadi stimulus peserta untuk memiliki semangat juang yang kuat, yang mandiri, teliti, dan ikhlas bekerja keras. Karakteristik tersebutlah, yang akan menjadi landasaran bagi CPNS untuk memulai bekerja dengan baik.

\section{Referensi}

Arends, R. I. (2013). Belajar Untuk Mengajar (9 ed.). Jakarta: Salemba Empat.

Balasubramanian, K. (2017). Moving towards borderless and limitless classroom: Blending Skype, Nearpod and Quizizz applications in the teaching and learning. Proceedings Of The International University Carnival On E-Learning (Iucel) 2017 (hal. 93). Bandar Baru Nilai: Centre for Global Open Access Learning. Diambil kembali dari http://creativecommons.org/licences/by-sa/4.0

BAPPENAS. (2019). Rancangan Teknokratik Rencana Pembangunan Jangka Menengah Nasional 2020-2024. Jakarta: BAPPENAS.

BPS. (2017, November 20). BPS. Dipetik Agustus 25, 2018, dari https://www.bps.go.id/statictable/2014/09/12/1176/jumlah-pegawai-negeri-sipilmenurut-kelompok-umur-dan-jenis-kelamin--desember-2007-dan-desember2016.html

Creswell, J. (2015). Riset Pendidikan, Perencanaan, Pelaksanaan, dan EValuasi Riset Kualitatif \& Kuantitatif (kelima ed.). Jakarta: Pustaka Pelajar.

Eser Çeker, F. Ö. (2017). What "Gamification" is and what it's not. European Journal of Contemporary Education, 6(2), 221.

Faruqi, U. A. (2019). Survey Paper: Future Service in Industry 5.0. Jurnal Sistem Cerdas, 2(1), 67-79. doi:https://doi.org/10.2505/jsc.v2i1.21

Ferreira, C. M., \& Serpa, S. (2018). Society 5.0 and Social Development. Management and Organizational Studies(5), 26-31. doi:10.5430/mos.v5n4p26

Fukuda, K. (2019). Science, technology and innovation ecosystem transformation toward society 5.0. International Journal of Production Economics.

Hadiyanto. (2017, Desember 20). kemenkeu. (kemenkeu) Dipetik Agustus 25, 2018, dari https://www.kemenkeu.go.id/publikasi/berita/cpns-kemenkeu-diharapkan-dapatmewujudkan-visi-kemenkeu/

Huisman, M. (2018, May). Formative Assessment and the Impact on Student Learning. Dipetik Agustus 19, 2018, dari https://nwcommons.nwciowa.edu/education_masters/86/

Iswan, \& Herwina. (2018). Penguatan Pendidikan Karakter Perspektif Islam Dalam Era Millenial Ir. 4.0. Seminar Nasional Pendidikan Era Revolusi "Membangun Sinergitas dalam Penguatan Pendidikan Karakter pada Era IR 4.0" (hal. 21- 42). Jakarta: Universitas Muhammadiyah Jakarta. 
9 Pancanaka Jurnal Kependudukan, Keluarga dan Sumber Daya Manusia Volume 1 No 1 Januari $2020: 1-9$

Jamro, M. (2017). Engaging students of Engineering \& Technology in positive Group Dynamics using randomly generated Instant Virtual Group (IVG) quizzes. International Journal for Innovation Education and Research , 5(10), 10-43.

Mashoedah. (2015, November). Kajian Penggunaan Media Pembelajaran dalam Pelatihan Peningkatan Kompetensi Profesional Guru. Jurnal Electronics, Informatics, and Vocational Education, 1(1), 17-25.

Mertler, A. (2011). Action Research Mengembangkan Sekolah Memberdayakan Guru. Yogyakarta: Pustaka Pelajar.

Moleong, L. J. (2015). Metodologi Penelitian Kualitatif. Bandung: Remaja Rosdakarya.

Mujiman, H. (2007). Manajemen Pelatihan Berbasis Belajar Mandiri. Yogyakarta: Pustaka Pelajar.

Nata, A. (2009). Perspektif Islam Tentang Strategi Pembelajaran. Jakarta: Kencana.

Prima, E. (2019). Tempo. Diambil kembali dari Tempo.co: https://tekno.tempo.co/read/1170120/mengenal-visi-jepang-society-5-0-integrasiruang-maya-dan-fisik/full\&view $=$ ok

Puspitasari, D. (2019). dewipuspasari. Diambil kembali dari dewipuspasari.net: https://dewipuspasari.net/2019/02/27/revolusi-industri-5-0-yang-humanis/

Puspitasari, S. S. (2018). Preferansi Struktur Organiasi Bagi Generasi Millennial. Jurnal Borneo Administrator, Vol 14 (2), 101-118.

quizizz. (2019). quizizz. Dipetik Agustus 15, 2018, dari https://cf.quizizz.com/static/getting-started.pdf

quizizz. (2019). quizizz. Dipetik Agustus 15, 2018, dari https://quizizz.com/resources

Salgues, B. (2018). Society 5.0 Industry of the Future, Technologies, Methods and Tools. London: Wiley.

Sugiyono. (2015). Metode Penelitian Pendidikan. Bandung: Alfabeta.

Suo Yan mei, S. Y. (2018). Implementing Quizizz as Game Based Learning in the Arabic Classroom. European Journal of Social Sciences Education and Research , 12(1), 208. Diambil kembali dari https://econpapers.repec.org/RePEc:eur:ejserj:483

Wahyudi Kumorotomo, N. R. (2015). Manajemen ASN. Jakarta: LAN.

Wanda, P. (2017). student.cnnindonesia. Dipetik Agustus 25, 2018, dari https://student.cnnindonesia.com/edukasi/20171219114411-445-

263408/pendidikan-dan-digitalisasi-di-era-milenial/

Wibawanto, H. (2016). Generasi Z dan Pembelajaran di Pendidikan Tinggi. Simposium Nasional: Mengenal dan memahami Generasi Z. Haruskah Pendidikan Tinggi Berubah? (hal. 1-10). Bogor: UPT Elearning Institut Teknologi Bandung. Dipetik Oktober 20, 2019, dari https://eportfolio4hariwibawanto.files.wordpress.com/2018/11/pembelajaranbagi-generasi-z.pdf 